\title{
The Exploring Visual Styles of Colours base on Studio Ghibli in "My Neighbour Totoro" Short Anime
}

\author{
Dahlan Bin Abdul Ghani and Halimaton Suhairiah Binti Abdul Jalil \\ Department of Animation, Malaysian Institute of Information Technology, \\ University Kuala Lumpur, 1016 Jalan Sultan Ismail, 50200 Kuala Lumpur, Malaysia \\ dahlan@unikl.edu.my, halimatonsuhairiah@gmail.com
}

\begin{abstract}
Colour is an element of visual language that people process before they are consciously aware of it. Each of these works explore creativity as a dynamic and multifaceted force and give away to large discussion of colour in background and characters. The aim of this research is to explore several visual styles of colour base in "My Neighbour Totoro" Short Anime. This study will focus on studying several elements related to colour such as tone (value), shading and expression in short anime.
\end{abstract}

Key words: Colour, visual, short anime, tone, shading, expression

\section{INTRODUCTION}

Physiologically, our discernment from claiming shade outcomes from changing wavelengths for light continuously reflected onto those retina which thus would transform toward phones known as photoreceptors (Brunick and Cutting, 2014). In the view of the eye, the colours interact with the brain of a mixture of the three primary colours of light such as red, blue, green combine certain positions. For examples of the mixture of red and blue can produce magenta colour. In terms of appearance, colour can reflect a certain reflection of light which is influenced by the pigment on the surface of an object. For example, magenta and cyan colour mixing with white light illumination will produce red colour. Each colour plays their respective roles. White symbolizes purity. The colour red symbolizes as a dominant and dynamic colour has an exciting (NAz et al., 2004). Green been discovered with have a resigning also unwinding impact. It excessively need both certain and negative impressions, for example, such that refreshment, quietness, naturalness and conversely tiredness also blame (NAz et al., 2009).

The main character in the film 'My Neighbour Totoro' using shades of grey and cream colours to stand out the character 'Totoro'. Background of the film is also use of natural colours such as green, brown, yellow and grey. Film 'My Neighbour Totoro' still use elements of the nature and cultural characteristics of Japanese society is also applied in the movie. The film reveals differences in the bright colours, dark and rain. The colour difference is very noticeable when it rains. They use dark colours to raise the situation of heavy rain. For Mei and Satsuki character is cheerful colour and its made they are different between gloomy characters. Every corner of the room dioramas used are various colours. Drawings and colour also made carefully though small. Home appliances also painted and stained. The aim of accentuating the atmosphere of the room or in of the house. Used a variety of colour schemes such as heavy cream, light cream and cream to fade in ne scene washed clothes.

Background of the study: 'My Neighbour Totoro' tells the story of a family move into an old house. Tatsuo Kusakabe has a wife and his wife have a long-term illness. When their move into the house, Mei and Satsuki find inhabited by tiny dust bunny. It called 'susuwatari' and look like small, dark, dust, house spirits when moving from light to dark place. The soot spirits leave the house when the girls and father become comfortable in their new house. One day, Mei found a small white, rabbit like ear in the grass and follow under the house. She discovers two small white who lead into the hollow of a large camphor tree. Mei meets and befriends a larger version of the same spirits. The spirits identify by a series of roars and she told the spirits is 'Totoro'. She falls asleep on the top the large 'Totoro' but when Satsuki finds her, she on the

Corresponding Author: Dahlan Bin Abdul Ghani, Department of Animation, Malaysian Institute of Information Technology, University Kuala Lumpur, 1016 Jalan Sultan Ismail, 50200 Kuala Lumpur, Malaysia dahlan@unikl.edu.my 
ground. Mei unable to show 'Totoro' to her family. Her father comforts her by telling that is the 'king of the forest'. The girls are waiting for their father bus and grow worried. When they wait, Mei fall asleep and 'Totoro' appears beside them. He has leaf o his head for protection against the rain, so, Satsuki offer the umbrella. 'Totoro' give a small gift to them and the inside the gift full of nuts and seeds. They decide to plant them in the garden. 'Totoro' board a bus shaped giant cat while taking the umbrella. A few days later, they awaken at midnight and find 'Totoro' and two white spirits engaged in a ceremonial dance. The girls join, whereupon the seed grow and combine become an enormous tree. In the morning, the tree gone but the seed have sprouted. One day, Satsuke get a telegram from hospital. She and Kanta goes to main house to telephone their father. While goes to main house, Mei follow them and lost direction. When they go back their house, Satsuki tell Mei that their mother will not be returning in the near days.

This led into an argument between them. Mei disappearance and Satsuki search for her. Satsuki return in desperation to the camphor tree and pleads for 'Totoro' help. Catbus carries her to where the lost Mei sits. Having rescued her, the Catbus take them to the hospital. They sit at the tree outside of the hospital and overhearing a conversation between their parents. They secretly leave the corn on the window where it is discovered by the parent and return home on the Catbus. In the end, mother Mei and Satsuki return home and the sister play with other children with 'Totoro' and his friend.

Literature review: Short anime 'My Neighbour Totoro' release April 16, 1988 Eggert (2010) 'My Neighbour Totoro' is short anime of traditional animation produced by Studio Ghibli Production which features the life and adventures. 'My Neighbour Totoro' may be in light of experience, circumstances also exploration. This gets reasonable in the flawless developed successions directing including 'Totoro' which need aid not fanciful Japanese backwoods creatures, however were really developed by Miyazaki Exactly to this motion picture.

Colour: Shades are rich with imagery. This imagery could be clear for how a singular co-partners shades for things, questions or physical space (NAz et al., 2009). Colour more light need aid acquainted with us from right on time childhood, they appear to be characteristic and we take them too allowed. A significant number colour inclination alternately colours acquaintanceships for diverse shades

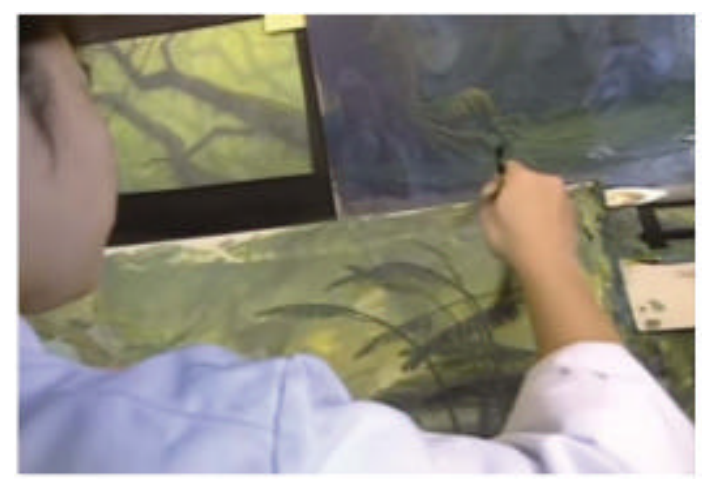

Fig. 1: A girl drawing a picture

however shift relying upon an individual's social or geographic, origin, age group, for example, kids, adults and elders. To shades that would acknowledged proportional at seen for those vital field from claiming vision, specific tasteful contrasts example brightness, hue and saturation were portrayed reliably over members the point when watched without confining the visual field. (Berenecker and Krueger, 2015). Mostly short anime Studio Ghibli using technique inking and colouring. At every last one of scenes have been animated they would take of the inking study. That is the place they pass the pencil sketches under cellulose. Cellulose will be a thin, reasonable sheet of transparent plastic. There they ink or photocopy the framework of the drawing onto cell, depending in they are completing it customarily or digitally. Initially, everybody inked those sketches eventually perusing hand and they might use all the considerable measure from claiming hours for simply a standout amongst them. Luckily for those innovation about computer those transform need turn into a considerable measure quicker furthermore simpler.

After they use gouache, acrylic alternately at whatever comparable paint on ass shades on the reverse sides of the cell. Again, on they are finishing it digitally, animators paint them for those workstations. For example, Fig. 1 the race of the shades may be exceptionally imperative. A colour palette might characterize those temperament of a scene and make it hotter or colder contingent upon the thing that they need to fulfil. A colour palette they using for reference like Fig. 2. There need aid masters in control for picking those colours for each span.

Shades have the capacity should transmit emotions, that's the reason animators use as palettes the point when finishing pitiful scenes, red ones at the grouping holds enthusiasm week scenes, like cherish ones or battling scenes and also brilliant shades for content minutes of the film. To pick those colours they consider the lightning of 


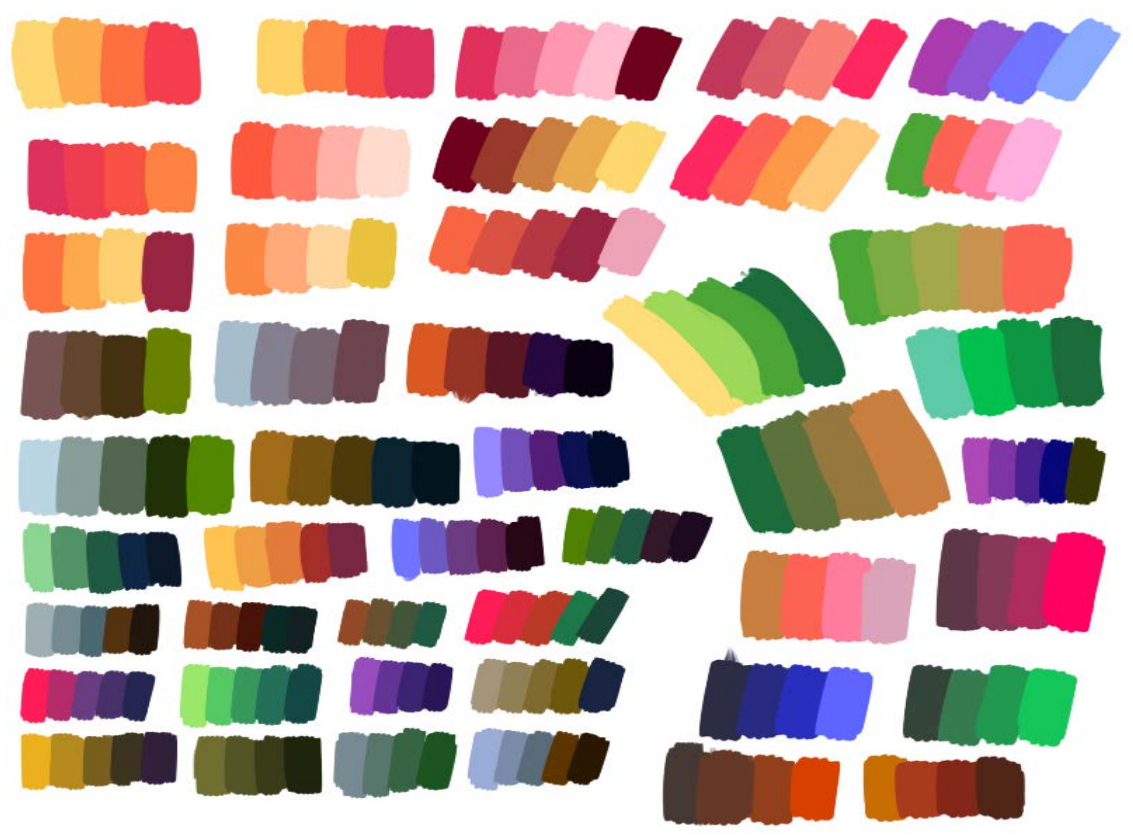

Fig. 2: Colour palette

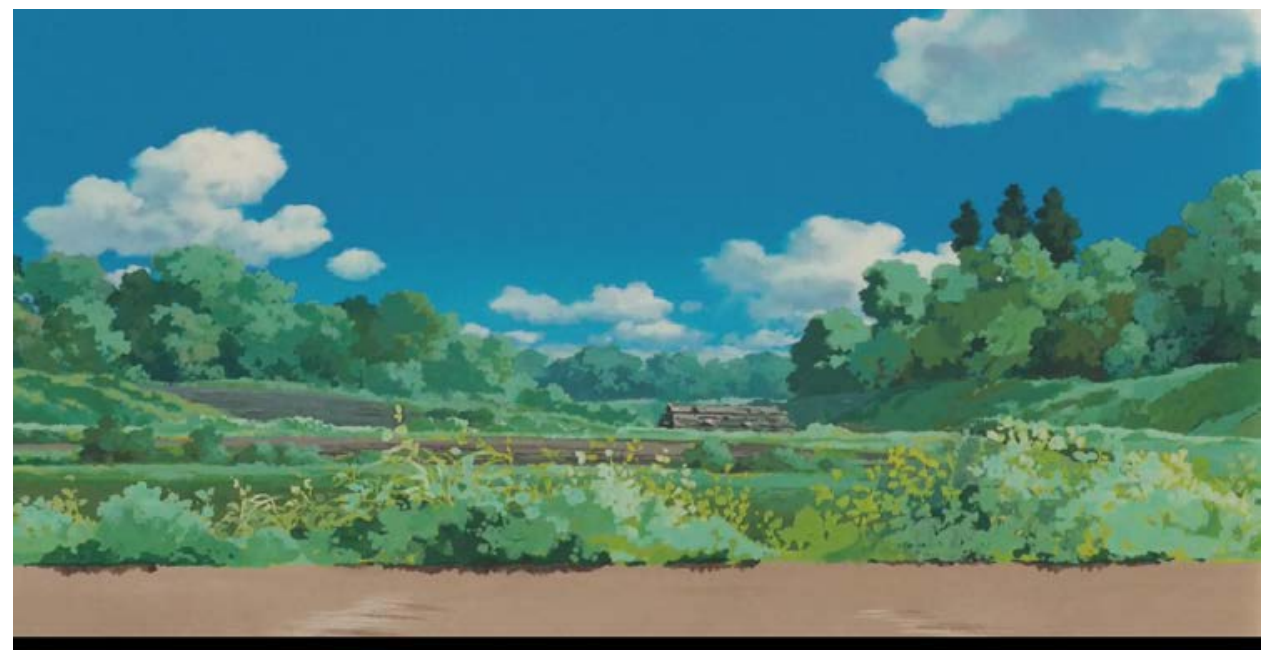

Fig. 3: Scene Sasuki and Mei come first house/neighbour

the scene those characters designs and so, forth throughout this way, observing and stock arrangement of all instrumentation (Moreno, 2014). 'My Neighbour Totoro' vivified arrangement need gave an alternate standard of e dutainment with perfect interactional utilizing different colour technique. In 'My Neighbour Totoro', Studio Ghibli using watercolour technique and others. For example, Fig. 3 using watercolour technique. Studio Ghibli famous with the art of background and technique colouring. Studio Ghibli using scheme colour like Fig. 4. Short anime such as 'My Neighbour Totoro',
Princess Mononoke, Spirited Away and Howl's Moving Castle using variety colour. For references look Fig. 4.

Meaning of short anime: Japanese animation, alternately anime is an immense business now a days, indeed in the United States. Understanding anime may be likewise, paramount a direct result anime may be an enormous powerhouse in the silver screen business also carries a considerable measure from claiming weight such as far concerning illustration purchaser conduct technique 


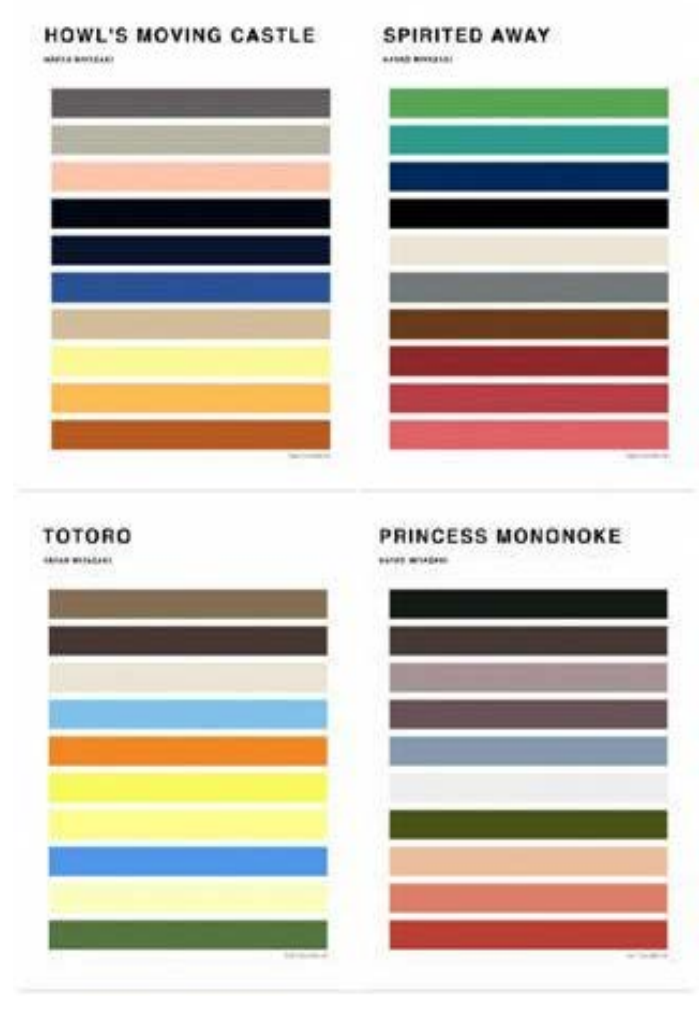

Fig. 4: Most colour palette in anime

dives. For example, purported 'American' well known icons have processed abundant income streams. Pokémon, Dragon ball $\mathrm{Z}$ and the ever-popular live action show, Power Rangers, might not a chance to be here though it were not to anime and the Japanese film industry. Anime which presently need a feasible business to America, might have been broadly dispersed through global robbery hones throughout those ' 80 's also ' 90 's. In spite of those vicinity about anime over present American pop culture, researchers predicted wrongly prior that anime might not survive in the West long because of social furthermore social disparities the middle of Western and Eastern animation (Chambers, 2012). Those expanding prosperity from claiming anime previously, later a long time need not run quite unnoticed by standard organizations. Thus, Stamp Segall in as much "Manga Entertainment: bringing anime of the next Stage," investigates how those 1st real merchant about Japanese animation for moderately "deep pockets" may be evolving things on a worldwide scale (Deneroff, 1996). Originally, domestically processed anime might have been planned mostly for children. In the mid-1970s those business dramatically expanded much appreciated will developing acknowledgement around more seasoned demographic from junior more senior high schoolers that demonstrated ripe ground to lucrative promoting fights. Toward those mid-1990s, expanding outside consideration prompted broad universal appreciation of Japanese anime. In 2013 and more much appreciated to vast some piece of the force of the internet, anime is generally distinguished concerning illustration a unique medium and the statement "anime" need much been embraced perusing large portions dialects around the universe.

However, indeed for Japan next to no consideration need been paid of the societal patterns that in this way profoundly affected the climb about Japanese anime concerning illustration a culture such as an after effect anime meets expectations have spread and formed fan bases abroad over an exceptionally independent, indiscriminate way (Hikawa and Sawaki, 2014). Top 10 in Fig. 5 Studio Ghibli short anime is 'Laputa: Castle in the Sky', 'My Neighbour Totoro', 'Grave of The Fireflies', 'Kiki Delivery Service', 'Porco Rosso', 'Pom Poko', 'Princess Mononoke', 'Spirited Away', 'The Cat Returns', and 'Ponyo' (Lamble, 2010).

Visual color character and background: Miyazaki's movies are most importantly outwardly enchanting, utilizing an watercolor search for the experiences furthermore, attempting inside the dissimilar japanese anime convention for characters for huge round eyes and mouths that could be similarly as little dot or likewise as a cave. Additionally, need a unforced authenticity in the approach they perceive details promptly clinched alongside "Totoro" to example those children take a gander at a little waterfall close to their home, also there on the bottom, unremarked will be a jug somebody tossed under those stream.

'My Neighbour Totoro' may be still hailed by huge numbers with make Miyazaki's best film also it's inarguable that it's as much a large portion unmistakable overall. It's a novel into a film that's gorgeous should take a gander at as well as will be reasonably inventive in the lifestyle it recounts its story. Same time the majority children's movies concentrate on a propelling narrative, typically very intricate to those demographic, filling in the encompassing zones for minimal comedic or movement bits, Totoro takes its duration of the time also gives things happen the manner life happens, laconically, situational, furthermore without keeping tabs ahead getting starting with purpose a will side of the point $b$ (Fig. 6). 

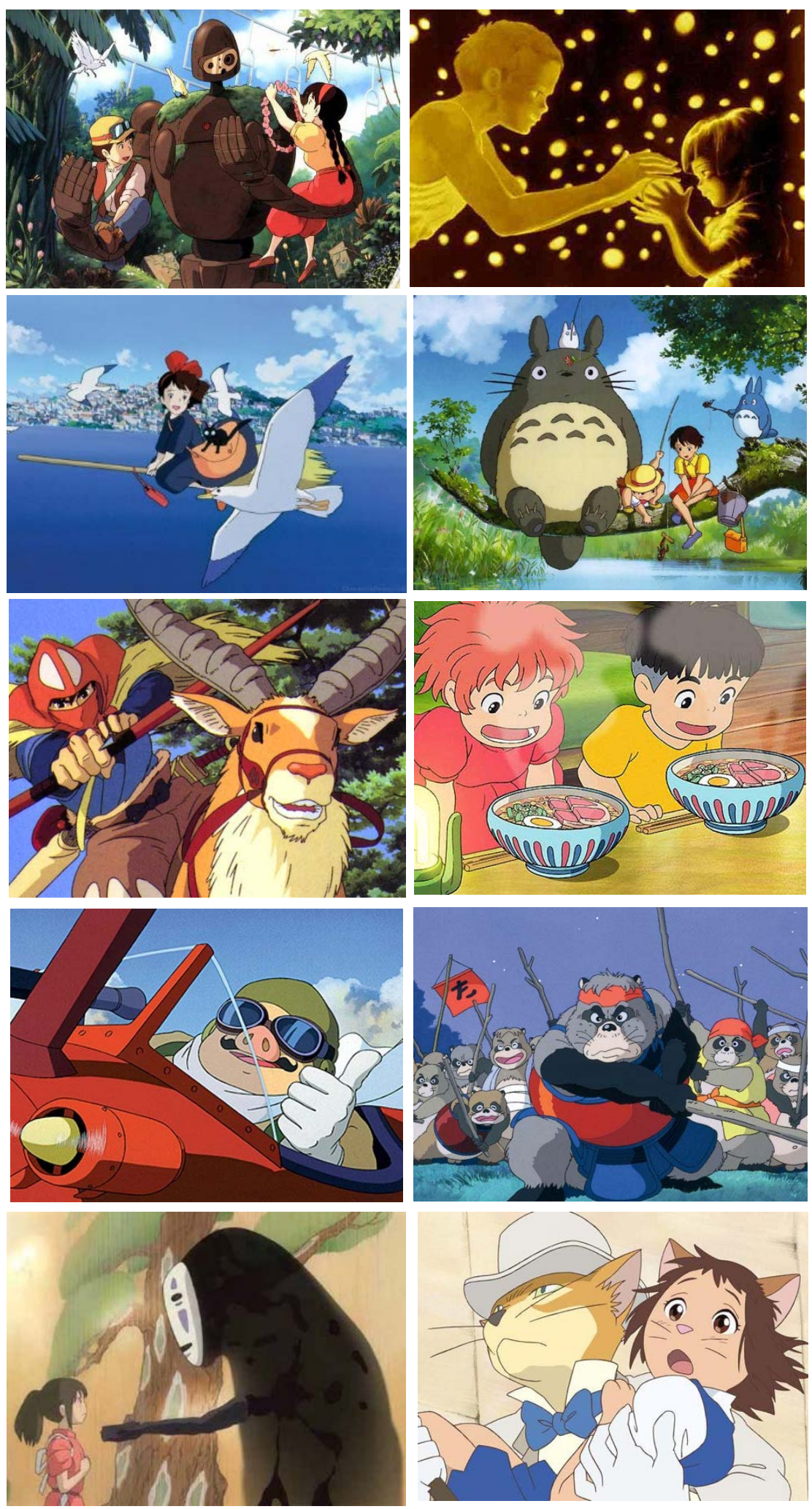

Fig. 5: List Short Anime by Studio Ghibli 


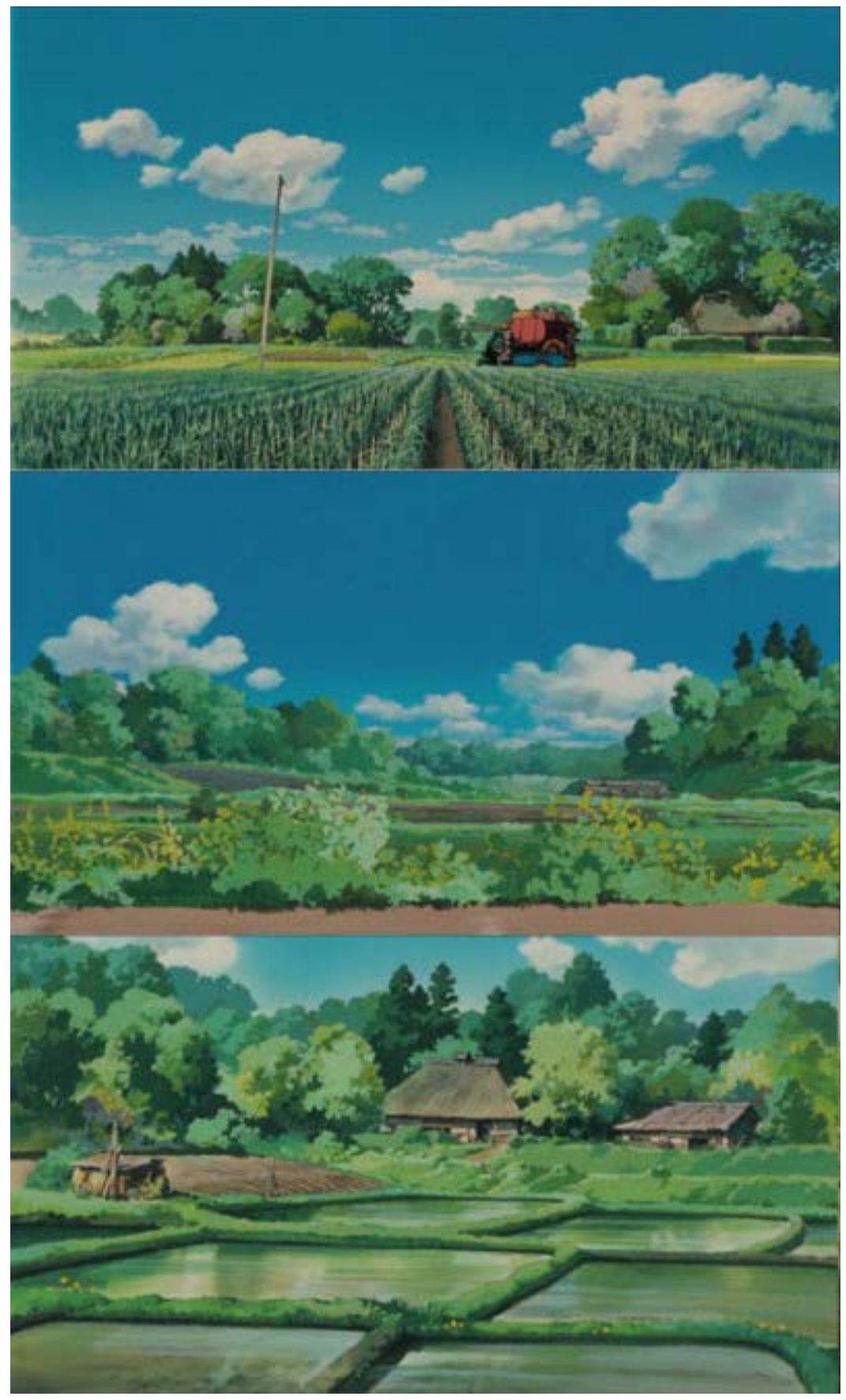

Fig. 6: 'My Neighbour Totoro' interesting visual colour of how character perspectives different

Anderson (2014) It's a novel into a film that has an inclination that adolescence there's generally no simpler path to set it. Mei (3) Furthermore Satsuki (10) about 'My Neighbour Totoro' are elated toward those possibility of beginning another an aggregation in the country and need aid enthusiastic will splash in the delectable scene around them. They delight in the excellence for their setting such as they drive through fields with their father. A side by side of this film, introduction of their natural landscapes (Fig. 6) offers an I nteresting visual colour of how character perspectives different. In as much as Mei and Satsuki panoramas are totally open, sun-kissed 


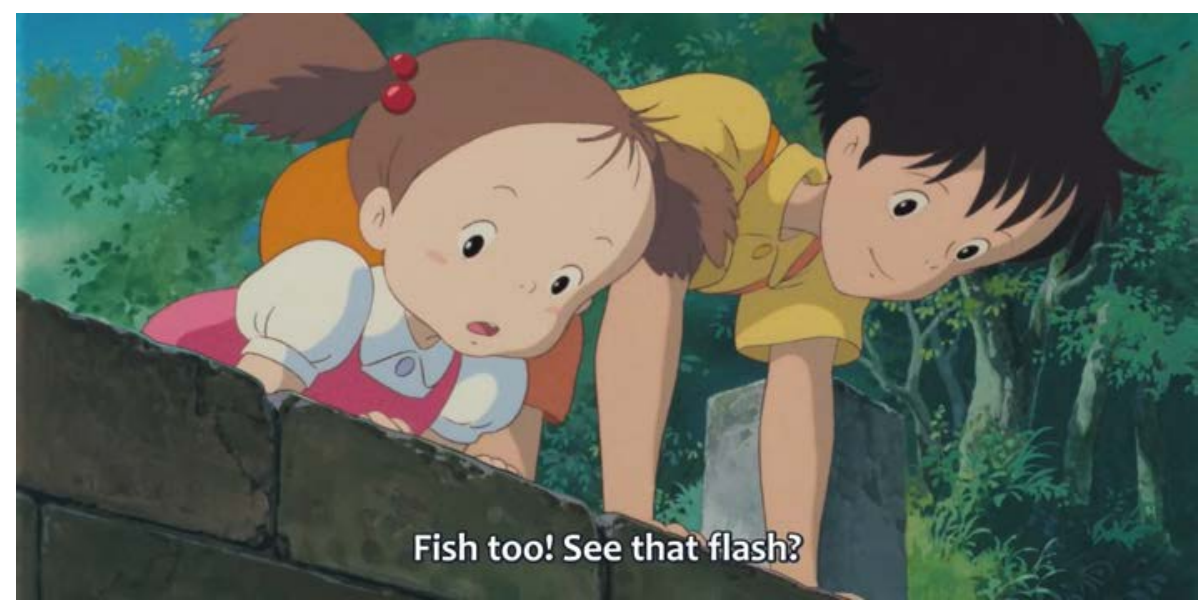

Fig. 7: The colour play important role to perceptive shot

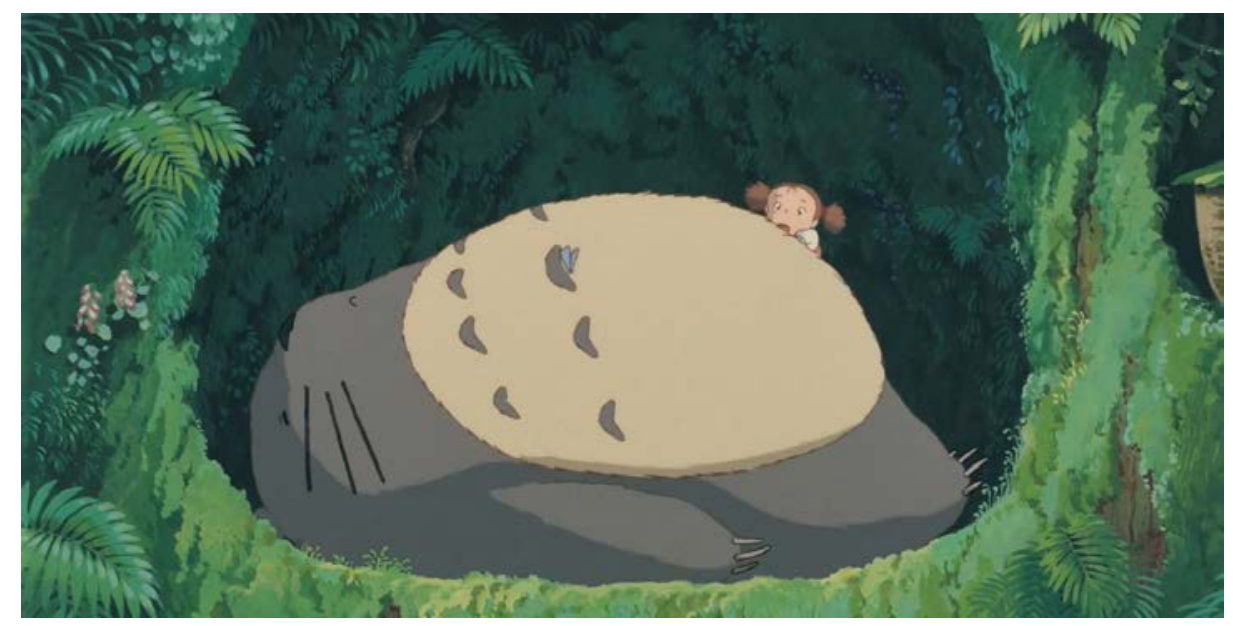

Fig. 8: Person specific scene highlights the vitality about convictions

spaces, the place the sky also clouds need space will inhale. Mei and Satsuki who need aid themselves skilled about finding enchantment for new air more acorns. Those first things these sisters discuss when they land at their new home are the fish in the close-by river and the charming tunnel about trees that acts such as a walk-way up to their house. They are consumed for way like Fig. 7.

Despite way may be pushed as important it will be not just nature however a most profound sense of being determined from way that is critical. This picture for spirituality, spoke to by Totoro (Fig. 8), really separates itself from way a couple times all around the nature into a film. Person specific scene highlights the vitality about convictions and would like through otherworldly existence in the face of a tenacious more merciless nature.
Mei and Satsuki find themselves holding up substantially longer over foreseen for their father will come back home from their mother's hospital, way abruptly gets to be a much all the more terrifying force; Sprinkle falls down upon those kids concerning they sit tight at a bus-stop and behind them the woods maybe dim more looming, unwelcoming a degree hazardous, manifestation as opposed for the sparse be that as warm streetlights. As time passes, uneasiness spreads and Satsuki get detectably hopeless Mei tumbles sleeping looking into her back and to the initially occasion when in the movie there will be an inclination of seclusion also despair what's more when the scene is at last brought to a resolution, it is not nature that acquires them solace, yet the spirit, Totoro (Recinos and Kudo, 2013). Those tone arm of the film is dreamy and playful such as Fig. 9. It 


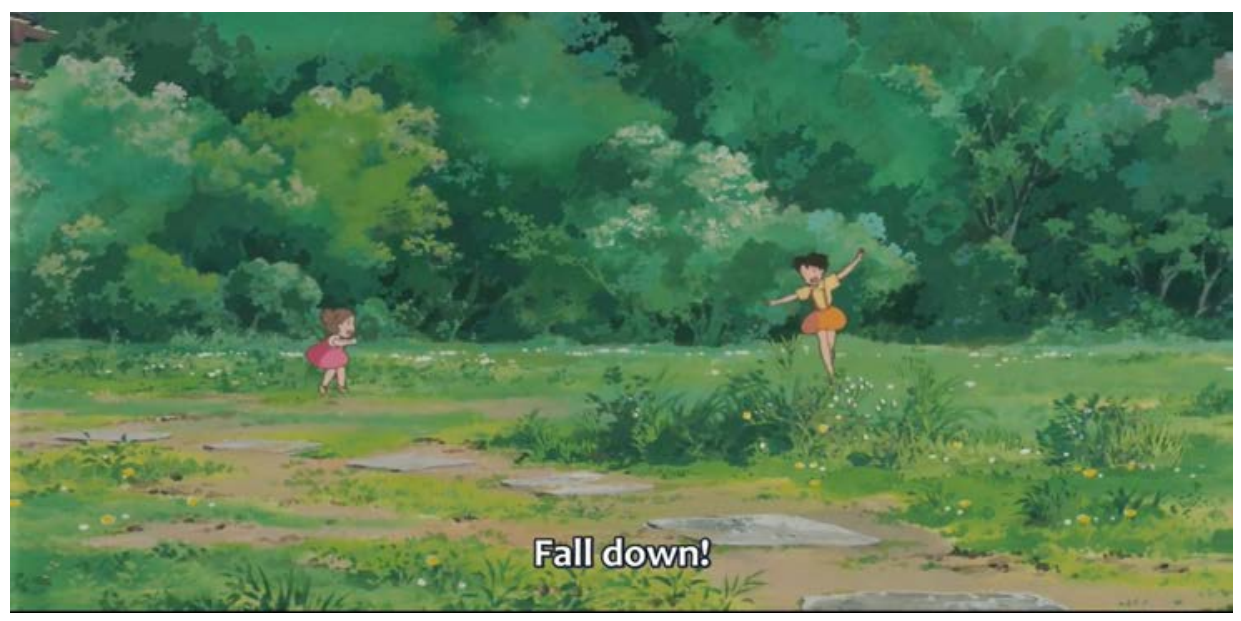

Fig. 9: Tone arm of the film is dreamy and playful

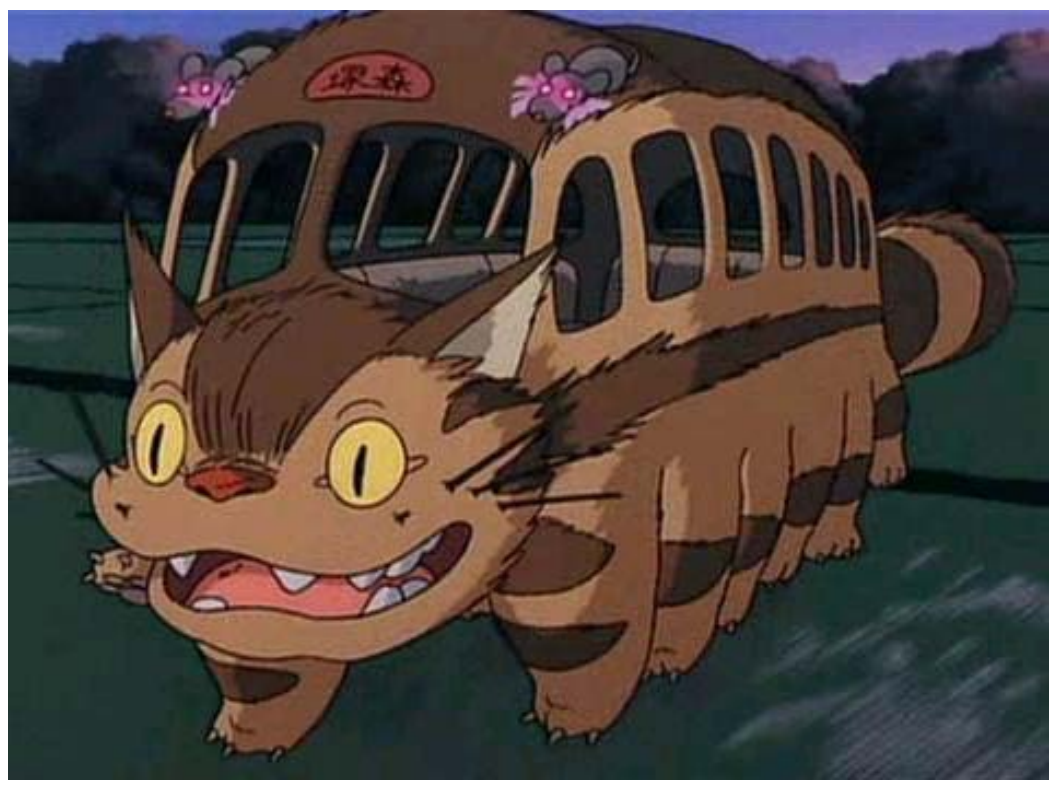

Fig. 10: The colour change to warm, golden, womb-like

need those sun-soaked shades furthermore, listless pace of a spring evening in the country but the manner it melds such components with an unpretentious treatment medicine of the children's tension over their mother makes it a radical novel into a film.

Satsuki, panicked and battling on a chance to be the mature sister, shouts in her not on this way "stupid", Mei runs away of the doctor's facility should find her mother. Both young ladies would rescue by the catbus (Fig. 10) which opens up a warm, golden, womb-like. Inner part on them an enchanting picture from claiming solace and limits over those wide open should return them with their father. Miyazaki may be an expert in passing on feelings such as a might experience them: obliquely, frequently physically with a string of supernatural considering that advertises flexibility. Miyazaki's movies are striking for their distraction with the environment and they're not totally figurative suggestive that those characteristic universes will be skilled from claiming recollecting what's been carried to it (Talbot, 2006) (Fig 11 and 12).

Culture: Japan the individuals longing should demonstrate this film done class ought to note that it holds a scene of a father showering for as much two little girls. Japanese groups frequently all the stake showering 


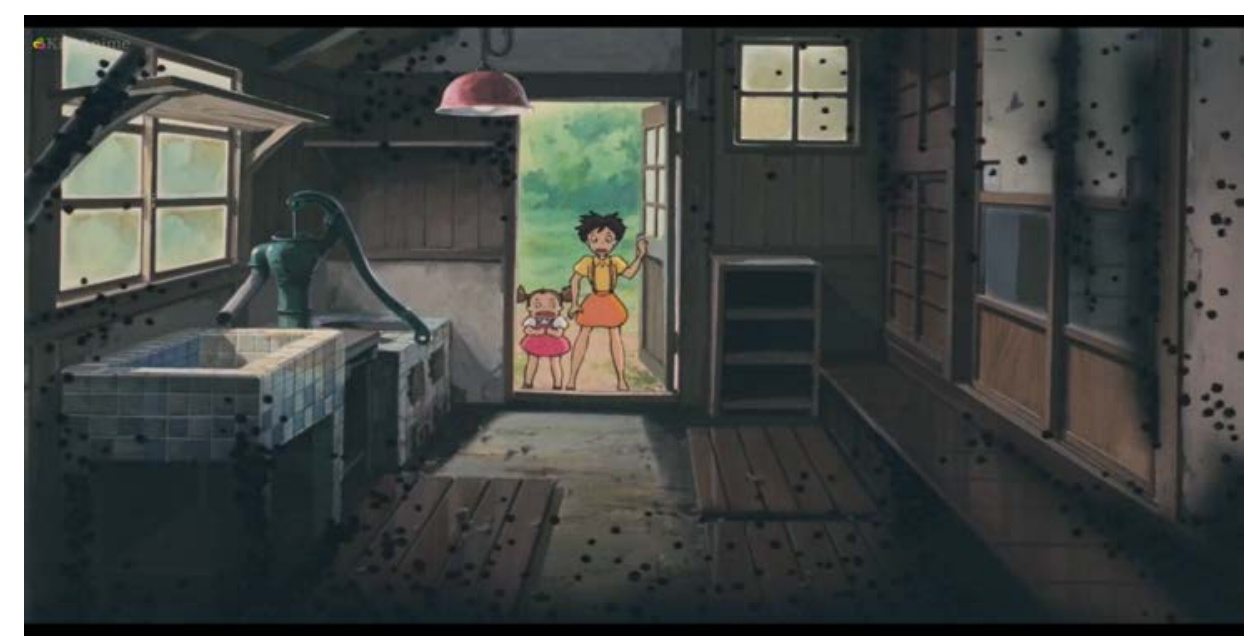

Fig. 11: Small, dark, dust-like house spirits seen when moving starting with light on dim spots

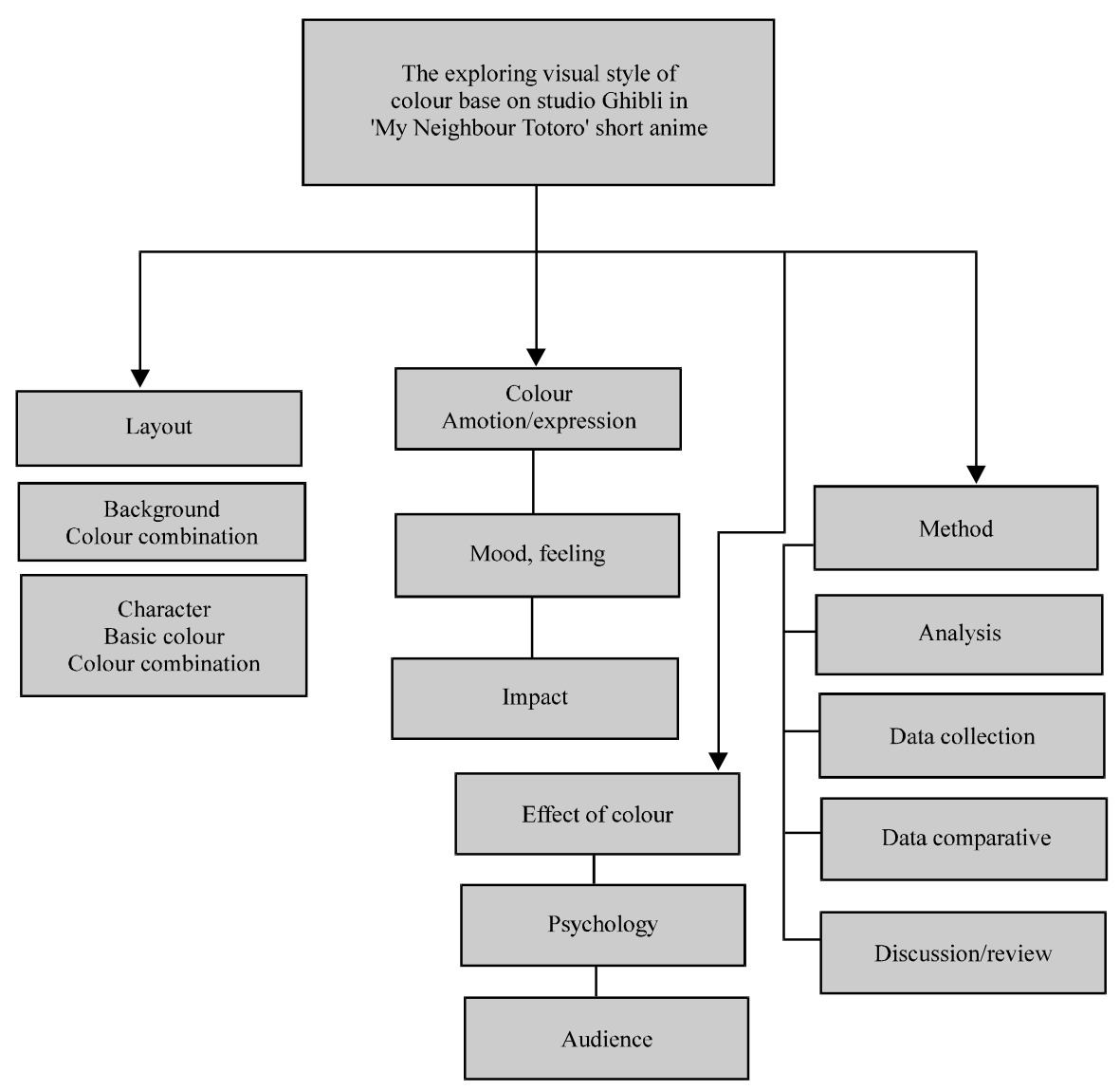

Fig. 12: Structure

facilities with kid's dependent upon through. Late basic school offering their shower duration of the time for one another or parents at home alternately openly bathhouses. Showering over may be exact unique in relation to those audience. Encountered with urban decay because of deindustrialization, engineering concocted, 
government lodge. One washes completely outside of the bathtub. The tub totally cleans on splash in really heated water, relaxing and frequently all the enjoying discussion with others.

Provincial term over Japan Satsuki and Mei an aggregation over 'My Neighbour Totoro' is a reasonably accurate, in nostalgic portrayal about provincial existence in Japan. The house under which the Kusakabe crew moves will be a typical, rural, Japanese home, more. Extensive over average city dwellings. The sliding entryways that adore for music, something she imparts to her father opens the point when they first move into those. House, opening those principle rooms of the outdoors, need aid normal engineering offers intended to make opened. Throughout those day, climate permitting and shut toward night.

An alternate characteristic of Japanese home an aggregation will be seen the point when those crew need should bed often, the extensive lounge room. Of such homes will be changed over under a room in night, the place the entirety gang sleeps together once stackable. Mats called futon. This dozing course of action is space-efficient also suits to more modest lodging for a nation the place living space may be extremely limited; expansive furniture may be infrequently seen clinched alongside conventional homes, for floor. The group to which Satsuki and her crew bring moved will be an ordinary Agricola region for rice. Paddies noticeable all around those film. Rice development may be a standout amongst the majority critical commercial enterprises On Japan such as rice (Totoro, 1988). "My Neighbour Totoro" is light of experience, circumstances also exploration, not ahead clash and risk. Small vivified dust animals known as susuwatari is small, dark, dust-like house spirits seen when moving starting with light on dim spots. When Mei and Satsuki get to be agreeable their new house snicker with their father, the sediment spirits clear out the house should float away on the wind. It is inferred that they are setting off to Fig. 11 and 12 another void house is their regular habitat.

\section{MATERIALS AND METHODS}

Research is common refers to a search for knowledge. When search a knowledge almost researcher using a method technique. According to Kothari (2004) research procedure maybe an approach should efficiently affect those research problems. The researcher keeps in the mind two types of method. The method is primary data and secondary data. The primary data is collection original data. This primary data included questionnaires, interview and observation or experiments. The secondary data is that data collect by someone. Mostly, the data in journal or article. This chapter will incorporate of the points of the technique used to make this research a complete and working appropriately. This method used to accomplish research that will obtain a flawless result. This $i$ will describes and discusses how this research will gather the data and information that will be using in this study. Method that use in this study is primary data and secondary data.

\section{RESULTS AND DISCUSSION}

\section{Significant statement}

Primary data; observation: I using the primary data for started this research. I exploring visual style of colour base on Studio Ghibli in 'My Neighbour Totoro' short anime with using the observation. I observe the short anime almost a week and collect the data while observe. When I watching 'My Neighbour Totoro' short anime, I analyse the visual style colouring what Studio Ghibli using the scheme and technique. I identify the scheme colour what they using like Fig. 13 for character.

'My Neighbour Totoro' has a sense visual style colourful colours. The colour Studio Ghibli used is the colour that appeared real life. This short anime has relied on the use of colour and lighting as mechanisms of effective visual story. I take a few scenes in ' $\mathrm{My}$ Neighbour Totoro' and I check the code for colour scheme what they use in this short anime. Mostly, I see colour for background and character have a same category colour such as green, blue, pink and yellow or orange (Fig. 14).

For Fig. 15 and $16 \mathrm{i}$ identify and analyse the visual style then I realize, the scheme colour based on Studio Ghibli in 'My Neighbour Totoro' short anime used a same colour. For forest they using green, dark green, blue-green and for the house using pink, soft pink. One by one scene they put that element for the audience. When audience ( $\mathrm{I}$ and my friend) watch this short anime we are excited with the visual background. I like the colour using in one by one scene. Mostly scene have a beautiful colour and visual. Visual character this short anime is great. I find the main character is cute, energy and positive. They using colour for Satsuki and Mei is yellow and pink.

Colour yellow is cheerful, happy, playful, optimistic and fun (Cerrato, 2012). I see in the main character. The character is Satsuki. When she plays with her sister she 


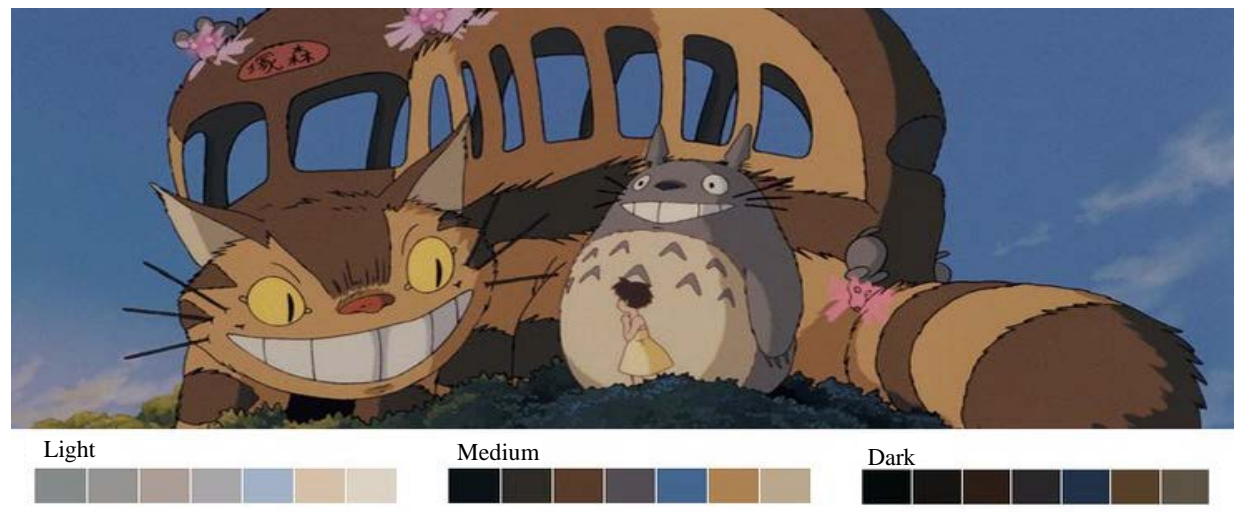

General spectrum

Fig. 13: Scheme colour for Totoro and Catbus

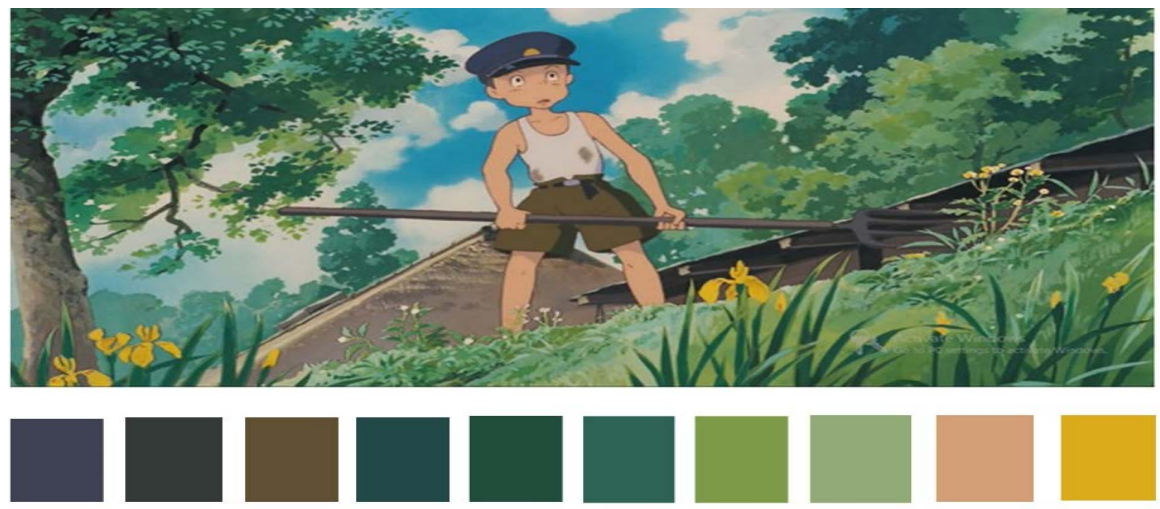

Fig. 14: Colour scheme

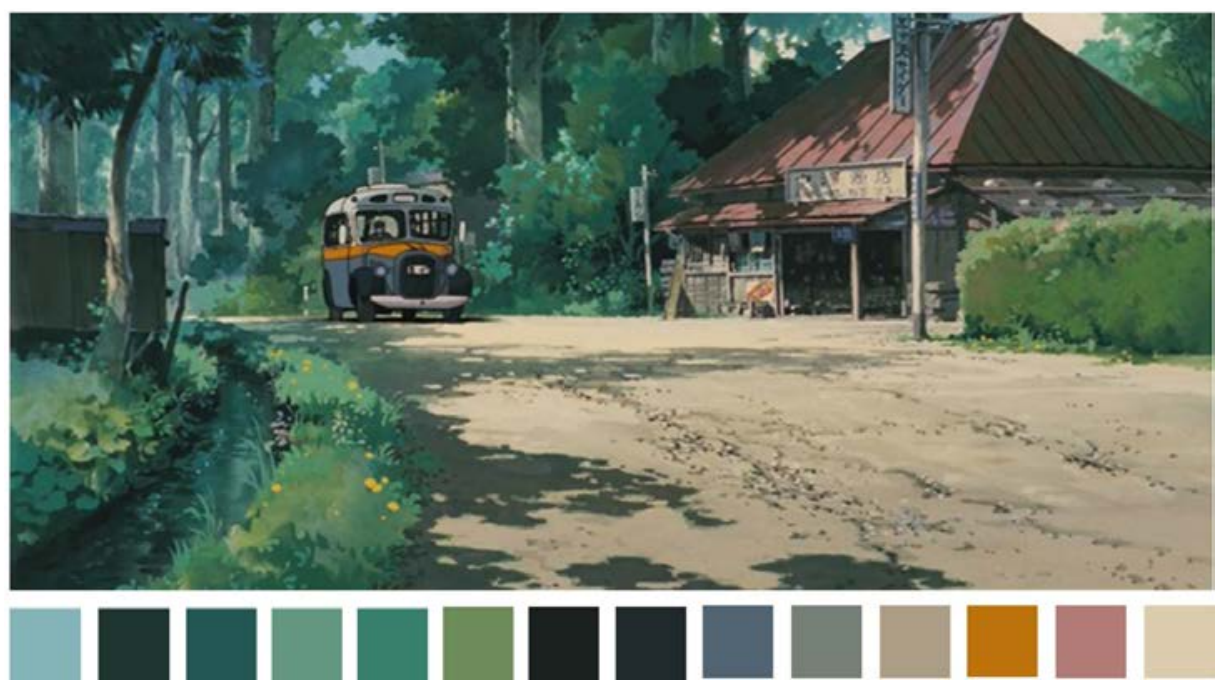

Fig. 15: Scene Kusakabe, Satsuki And Mei On the Way Goes to A New House 


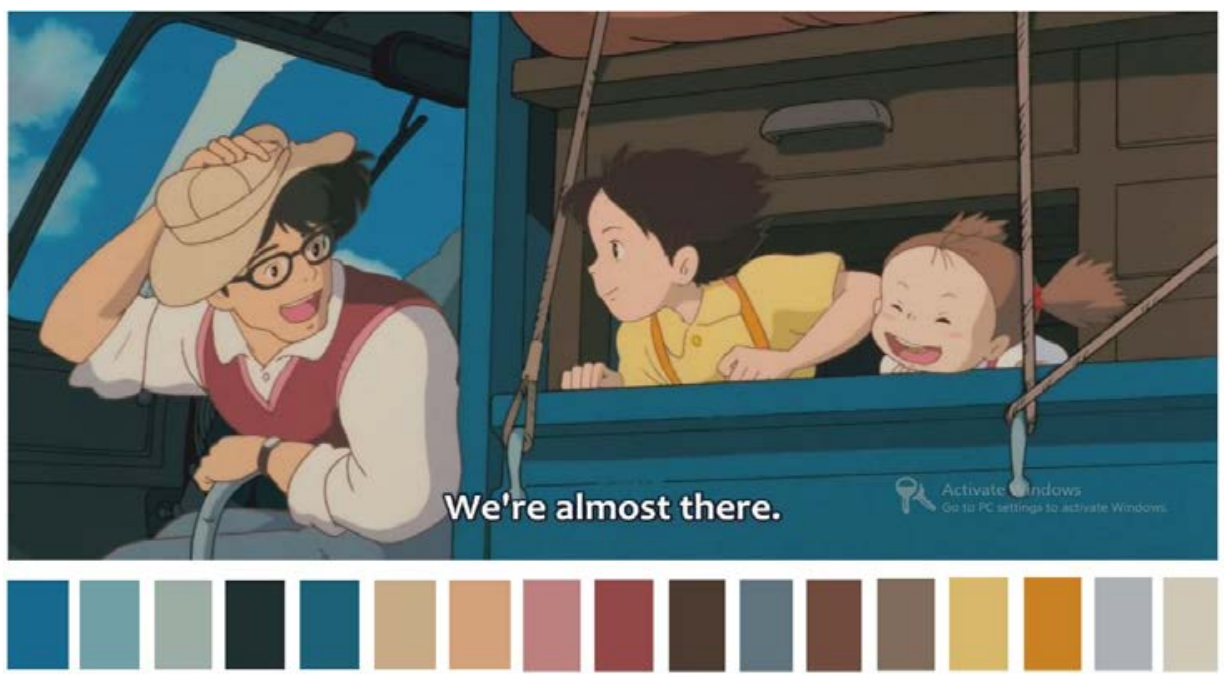

Fig. 16: Scene Kusakabe tell Satsuke they almost arrive at the village

very playful and happy. Their mother talks about the haunted house and Mei asking her mother like or not and her mother answer the question 'yes and can't wait to see ghost' and Satsuki say 'of course mother like and don't worry about that'. Satsuki very optimistic about surrounding her sister. She became positive and confidence. Colour pink as an immature, silly and girlish. Mei personality bright, sweet, caring but a bit immature because she only 4 years old.

\section{CONCLUSION}

In decision will generating a short anime or film that a considerable measure from claiming things that have will make viewed as with get a great motion picture. Different stage more procedures must be implementable should settle on a sway a film. The utilization about colouring strategy right more will hint at extraordinary liveliness. Fitting period management may be irreplaceable in the processing for quality animation. Huge sacrifices must make made to guarantee that the time on complete the one task runs smoothly. I trust that my research will run this effective more permitted me with open the eyes of the open that the utilization of a procedure about colouring animation short film could be generated all the with handy personal satisfaction.

A colour need obviously connoted the vitality from claiming animation, describing those workmanship about how it communicates for the group of onlookers to furnish edutainment. It need conveyed a solid message through narratives and characters. Foundation archetypes, motives in the film. For practically (if not all) animation, shade may be reflected through different mediums. A percentage would reflect the physical vicinity about characters or backgrounds. Some are reflected for those visual colours inside the animation/anime. Since, the start about animation, individuals need utilized what they see around them with create plots and story. It (anime) is a worldwide. Pattern in which on exceptional understood, the more profits we could procure crazy about global personality of animation/sort anime. This research methodology used a primary data and secondary data. Observation data were administered by researcher herself to collect data based on Studio Ghibli 'My Neighbour Totoro' short anime. The sample characteristic included screenshot and colour scheme. This chapter described the research methodology including data collection such as figure as well as strategies used to the ethical of the study.

\section{ACKNOWLEDGEMENT}

I would like to thank Animation and Creative Multimedia department lecturers at University Kuala Lumpur for all the support given throughout conducting this research. This research will hope to inspire more research about colouring technique that applied to animation and how important and colour scheme for make animation more interesting.

\section{REFERENCES}

Anderson, K., 2014. Miyazaki masterclass: My neighbor totoro. Nerdist Industries, Burbank, California, USA. https://archive.nerdist.com/miyazaki-masterclass-m y-neighbor-totoro/ 
Besenecker, U.C. and T. Krueger, 2015. Luminous color in architecture: Exploring methodologies for design-relevant research. ENQUIRY ARCC. J., 12: 35-46.

Brunick, K.L. and J.E. Cutting, 2014. Coloring the Animated World: Exploring Human Color Perception and Preference through the Animated Film. In: Cognitive Media Theory, Nannicelli, T. and P. Taberham (Eds.). Routledge, Abingdon, UK., ISBN:9781136226106, pp: 124-138.

Cerrato, H., 2012. The meaning of colors: How colors impact our daily life in business, art, work and love. Herman Cerrato Mosaics, Greece, Balkans. http://www.hermancerrato.com/ graphic-design/ images/ color-images/ the-meaning- of-colorsbook.pdf

Chambers, S.N.I., 2012. Anime: From cult following to pop culture phenomenon. Elon J. Undergraduate Res. Commun., 3: 94-101.

Deneroff, H., 1996. Woman in animation. Animate the World, Breda, Netherlands. https://www.awn. $\mathrm{com} / \mathrm{mag} /$ issue 1.2/AWNMagOpt1 .2.pdf

Eggert, B., 2010. My neighbor totoro. Deep Focus Review, USA.
Hikawa, R. and D. Sawaki, 2013. Japanese animation guide: The history of robot anime. Mori Building Co., Ltd., Roppongi Hills Mori Tower, Minato-ku, Tokyo, Japan. http://tohno-chan.com/ddl/src/Japanese Animation_Guide_The_History_of_Robot_Anim.pdf Kothari, C.R., 2004. Research Methodology: Methods and Techniques. New Age International Pvt Ltd, Delhi, India, ISBN:9788122415223, Pages: 401.

Lamble, R., 2010. Top 10 Studio Ghibli movies. Dennis Publishing Company, UK. https://www.imdb.com/ list/s069746612/

Moreno, L., 2014. The creation process of $2 \mathrm{~d}$ animated movies. Scribd Inc, San Francisco, California, USA. https://www.scribd.com/document/306562223/TheCreation-process-of-2D-animated-movies

NAz, K., H.H. Epps and D. Hall, 2004. Relationship between color and emotion: A study of college students. Coll. Stud. J., 38: 396-405.

Recinos, B. and H. Kudo, 2013. Hayao Miyazakis World, Best of Booklet. Kyushu University, Fukuoka, Japan, Pages: 108.

Talbot, M., 2006. The auteur of anime. Asia Pacific J. Japan Focus, 4: 1-17.

Totoro, T.N., 1988. Film overview: My neighbor totoro. ?Studio Ghibli, Koganei, Tokyo, Japan. 